\title{
4 \\ How to deliver better infrastructure planning
}

\author{
Philip Davies
}

Soon after the delivery of the speech on which this chapter is based, Infrastructure Australia (2016) released its 15-year Australian Infrastructure Plan.

The plan was developed following consultation on the Australian Infrastructure Audit and recommended fundamental changes to the way Australia plans, funds, delivers and uses its infrastructure.

It had 78 recommendations for reform and was structured around four main themes:

- $\quad$ productive cities, productive regions

- $\quad$ efficient infrastructure markets

- $\quad$ sustainable and equitable infrastructure

- better decisions, better delivery.

Alongside the plan, Infrastructure Australia released a new Infrastructure Priority List, which identified 93 projects and initiatives around the country. The list provides rigorous, independent advice to governments and the public on the infrastructure investments Australia needs.

Infrastructure Australia will update the plan at least every five years and the priority list regularly throughout each year.

For more information and to download the plan and the priority list, go to www.infrastructureaustralia.gov.au.

The public discussion on infrastructure is often constrained by focusing on specific projects, rather than long-term policy and strategy, and there are certainly some challenging opportunities in front of us-not least those identified in Infrastructure Australia's recent audits. We see growing population levels, and the recent audit suggests we could face an annual 
cost of traffic congestion of $\$ 53$ billion by 2031 . We also have governments grappling with budget constraints and long-term environmental concerns. On the other hand, we are seeing continued economic growth and an increase in demand for infrastructure services-and most of these are good signs. These are signs of the success of the nation; however, unless we engage with some of these challenges now, we are going to wake up in the future and realise our quality of life is not what it used to be.

\section{Auditing existing practices and demand projections}

This chapter focuses on the importance of long-term integrated planning, particularly the integration of transport and land use planning. As a starting point, I will take the opportunity to set the scene somewhat in terms of what my organisation, Infrastructure Australia, does and what our role is in providing leadership. Infrastructure Australia's role includes being an advisor to governments, as well as to investors and owners of infrastructure, through the whole life cycle of their assets, but particularly around policy and planning. In mid-2014, with bipartisan support, the Infrastructure Australia Act was amended, setting up Infrastructure Australia as an independent statutory body with a mandate to prioritise and progress nationally significant infrastructure. The Act also established a 12-person board and the right to appoint a CEO. I was appointed in 2015 , and we were already in the throes of some fairly significant activity relating to planning, including the release of the Northern Australia Audit and the Australian Infrastructure Audit, both released in May 2015. Both documents highlighted the need for action and provided an evidence base from which to build our future plans.

The Australian Infrastructure Audit in particular took a long-term view, out to 2031. It considered some of the key drivers of demand and identified some of the challenges we will face if we do not act (it is very much about if we do not act); this evidence base is what we have now drawn on, working closely with states and territories, to start to identify some of the solutions we think will address the challenges. These issues were brought together in the 15-year Australian Infrastructure Plan, which was released in 2016. 
One of the key findings of the Australian Infrastructure Audit was that, after 2031, we are likely to face an increase in population of 40 per cent-to about 30.5 million people, as indicated by Figure 4.1. At present, our population - to put it into context-is the fastest-growing among the members of the Organisation for Economic Co-operation and Development (OECD). Most of that population growth is forecast to be in our four largest capital cities: Sydney, Melbourne, Brisbane and Perth. Figure 4.2 indicates the projected growth of these four cities. There are two questions we have to ask ourselves. First, what does the increase in population in our cities mean for how these cities will operate and function? This is an important question because the major cities are projected to grow, by 2061, to a size comparable with London, New York and Paris today. This means we need to think differently about how our major cities operate. Second, what are the outcomes we want, and are there opportunities to grow some of the smaller capital cities in a different way so we can spread the load and make better use of the infrastructure we already have in those cities?

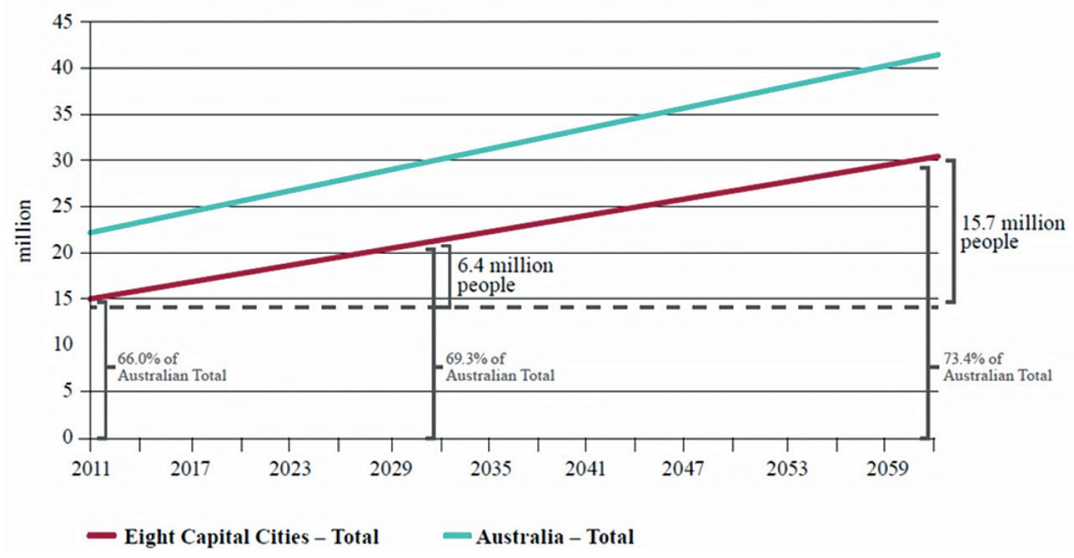

Figure 4.1 Australia's projected population growth to 2061

Source: Infrastructure Australia analysis of data from ABS (2013a; 2013b: Series B). 


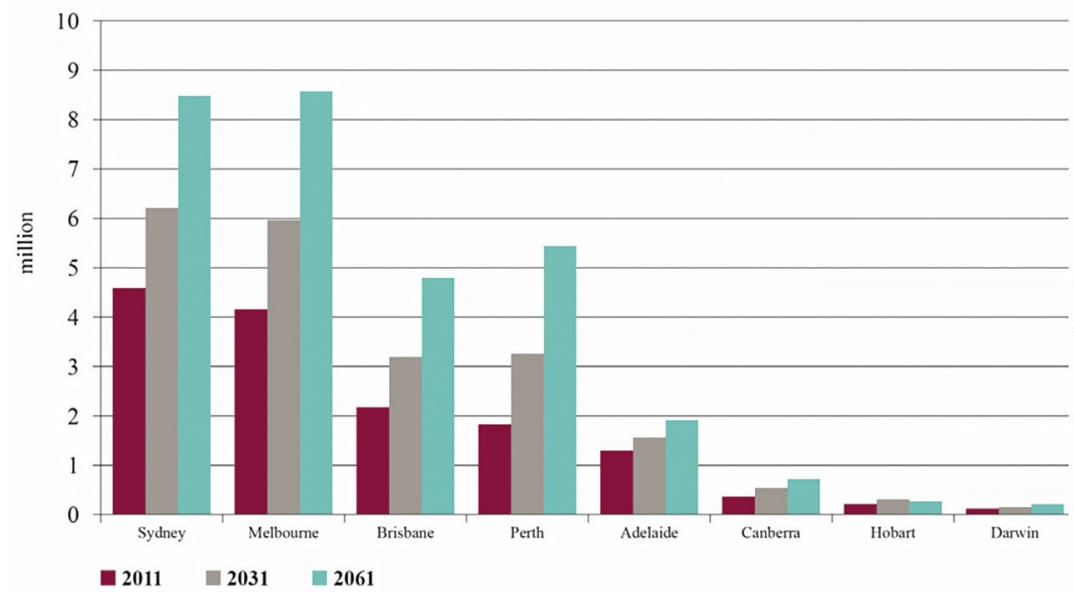

Figure 4.2 Projected population growth in Australian capital cities to 2061

Source: Infrastructure Australia analysis of data from ABS (2013a; 2013b: Series B).

\section{Reiterating the need for long-term planning}

It is crucial we embrace this opportunity to shape and plan not only our cities, but also our future infrastructure needs. This is not an easy role. It is fair to say we have moved away from long-term planning in recent years and have become very focused on the short term-largely on major projects. We need to get back to basics with regard to strategic planning, at the regional, city and national levels. More so than in the past we are seeing a great deal of change, such as demographic change, with an ageing population, shifts in the patterns of demand and much disruption, which is spoken about a lot-but not all of this disruption is bad. Most of us appreciate that this disruption presents a great opportunity, particularly to connect with the community and take them on a journey. We are seeing global economic shifts and changes in the way we go about doing our work. Unfortunately, despite the importance of these challenges, longterm planning is missing somewhat, and our project pipelines are relatively short. Addressing these issues is the call to arms we have picked up, along with our colleagues, around the country in developing this 15-year plan.

We have identified a number of key trends. One is that, in Australia, we have moved away from planning and feasibility studies. These were a big feature in the past, but are not so much a feature today. We have also 
moved, on occasion, to committing funding to problems before they are turned into solutions and fully developed as projects. We have also not had enough focus on getting the most out of the infrastructure we already have-something touched on in the previous chapter. One of the things Infrastructure Australia is focused on, therefore, is the better use of what we already have, before we rush off to plan a new project. Yet, as a result of this lack of a pipeline, we in Australia are not consulting enough with the community. Often our conversations come very late in the piece and do not bring the community on the journey. Currently we are undertaking a small number of post-completion reviews, which often highlight that our previous infrastructural projects appear to be examples of lost opportunities. Ex-post reviews give us the insight into the outcomes that were delivered, so we can learn from our good work as well as our bad work and feed that back into the next project.

Some of the benefits of long-term planning tend to run counter to the abovementioned points, and a return to long-term planning will help address many of the major issues we face. We must recognise that projects generally cannot be delivered overnight; they take years of planning before we can give them a green light and have them ready to proceed. A return to long-term planning at the state and federal levels means we will have an observable long-term pipeline of up-and-coming projects. To date, the general absence of that pipeline of projects has meant the supply chain has also suffered, so it is not just about the people involved in delivering these projects within government; it is also about the downstream supply chain. Without a long-term pipeline, suppliers are not able to plan their resources and their capability, and employers are not sure whether they should recruit, retain or train staff, especially in some specialised areas. Subsequently, Australian taxpayers pay the cost for that.

\section{Improving our planning capabilities}

There are a number of key areas for improvement in planning. First, there is real need for higher-quality data to underpin our decision-making, and this is certainly something we found while conducting the Australian Infrastructure Audit. Access to data is still a challenge. Second, there is much discussion about integrated land use and transport planningor integrated land use and infrastructure planning - yet it does not happen. In particular, we have moved away from protecting transport corridors. 
Third, there is a growing need for greater transparency and rigour in our project selection processes. Fourth, as mentioned above, there is a need for ongoing ex-post reviews, as these provide learning opportunities.

In terms of data, we have certainly seen a lack of quality across most sectors. We found in the audit that it was particularly challenging to collect data on the operations and maintenance of assets, the performance and delivery of infrastructure, the services and service levels the infrastructure is delivering and the cost of maintenance. As Marion Terrill argues in Chapter 3 (see Figures 3.2 and 3.6), we are investing a lot in infrastructure, but perhaps not paying enough attention to how much we need to be spending on maintenance and operations. This may sound somewhat pessimistic, but we are not alone in facing these challenges. The most recent period has been about supporting the mining boom, building up our infrastructure and getting the country going; and, in such circumstances, it is unnatural to focus on sweating assets and driving performance improvements. So, this is not a problem we have; it is more a matter of shifting our focus.

I previously worked in the United Kingdom, with responsibility for operating London's roads, and, despite the levels of congestion in London and the challenges there, we had exactly the same issues. The maintenance funding would often be spent on things other than maintenance. For instance, there were about 6,000 traffic signals in the city and, when I took over responsibility, no one had looked at timing the traffic signals for some 27 years. In effect, they were installed and subsequently forgotten about. London at the time was a city going through significant growth and experiencing significant congestion, with a good deal of pressure to address those issues. But it had not been done because it was not the focus of the times. I use this example as a kind of baseline to show that we know we are not alone in this; we just need to shift our focus.

Having said that, another area we could improve on is thinking about systems and networks. We need to gain a better understanding of how infrastructure actually works together (intermodally). When we are project focused, it is easy to avoid thinking about the bigger picture, how the solution fits into a network and how we can make the system work as a whole. When looking at pieces of a supply chain, it is important to consider the whole chain. With these challenges in mind, our 15-year plan has some suggestions about how we might address them. 
In terms of the evidence base, we found some gaps in data availability, but what we did do well in the audit was some detailed modelling, particularly around some of the transport corridors in our capital cities. We looked at what that estimated $\$ 53$ billion worth of congestion actually looked like in terms of transport corridors. That has certainly been very helpful in the planning process on which we have embarked with the state and territory governments-looking at what the solutions might be and then using those to inform the plan. And, in the interests of sharing access, we have made our assembled data available to all. There is now an awful lot of data on our website if anyone is interested in looking at it, and some regional development agencies have already been using it for their own planning purposes. Obviously, we need to build this evidence base over time, and that is something Infrastructure Australia has been talking with the Commonwealth Department of Infrastructure about.

Integrated transport and land use planning is an important function that can be improved. And it is not just about moving people; it is also about moving goods. Infrastructure Australia's audit predicted that we will see a doubling of land freight volume to 2031. Particularly around some of the larger capital cities, we are approaching circumstances similar to something I experienced in the late 1990s in Japan, where there was a 'game change' in terms of how goods were distributed around Tokyo. Although Tokyo is a much larger city than any of Australia's capital cities hopefully will ever be, there was a real shift in terms of how goods were distributed through the city, and that is the type of thinking we need to adopt here.

What we tend to find today is that the planning and provision of infrastructure and land use are still often undertaken in silos, with different government departments responsible for different aspects of the infrastructure network in terms of its planning and delivery, and, as a result, we do not necessarily get the outcomes we need or deserve-and that is one of the reasons we do not think at the systems level. Therefore, we are very focused on how we think about planning. On occasion, our cities are not planned in the best way, and in the context of the growth we are expecting, this is something to which we really need to pay attention.

As a first step in long-term planning, we are looking to work closely with state and territory governments, where we can play a role in challenging how we think about planning as we bring this 15 -year plan together. Another thing we have done well in the past, but not so well recently, is 
to protect transport corridors - one of the benefits of which is that we can accommodate future projects at a reasonable cost. History demonstrates that corridor protection is an important element of long-term planning.

Between the 1950s and the 1980s, a number of state governments protected corridors that enabled major projects to be built, such as the West Link M7 in New South Wales, the East Link in Victoria and, in recent times, the Badgerys Creek Airport site in Sydney. Many of these sites were set aside some 10 to 20 years before the project commenced. So there is evidence that state governments have had some success in longterm planning, but corridor protection has often been overshadowed by a short-term focus in recent times.

Another area of discussion is the transparent project selection process; and, once having done a good job of the long-term planning, it is important to ensure we have a rigorous process for evaluating our projects and that our projects are adequately solving the problems we need to solve. Options to solve some of these problems need to be appropriately identified and scoped, and we do not need to attempt a new solution all the time; we also need to be thinking about how we can improve what we already have. For example, would new signalling on a rail system actually provide greater benefits than building a new rail line?

\section{Infrastructure Australia's strategic advisory role}

Infrastructure Australia is required to undertake an assessment of all projects of national significance over $\$ 100$ million for which Commonwealth funding is sought. Despite what some people think, we do not develop our own business cases and we do not make decisions regarding the funding of projects. Our role is that of an advisor and an assessor of the solutions presented, and hopefully we have been involved in developing these solutions early in the piece, where we can provide useful input and advice. We do assess the cost-benefit of projects, we make those assessments public once they are completed and we have a rigorous methodology for conducting the assessment. We look at strategic fit-how that solution fits into the wider network-how it addresses the problems of national significance that have been identified, at the evidence that has been provided and at the economic viability. Importantly, the proposal must have a clear delivery plan and be deliverable and realistic. 
In terms of oversight, the Department of Infrastructure plays an important role. Once Infrastructure Australia has completed its strategic planning role, the department will often oversee the project when it is to receive federal funding.

An area where we in Australia really could do better is in assessing the outcomes of projects. Once the planning and implementation of the project are complete, it is crucial that we measure the outcomes, understand whether we delivered the benefits in the business case and the broader outcomes of some of our investments, in terms of not only the project, but also its impact on the community and its fit into a system or a city or wherever it might be. These outcome assessments are necessarily long term in their approach. We might measure these things when we implement a project, we might need to measure them five years later, 10 years later or so on, and without that kind of evidence it is difficult to improve the way we do our planning; this is something on which we need to focus.

Having discussed many of the challenges and some of the improvements in planning we could make, what has Infrastructure Australia's role been in supporting some of these processes? We are keen to play our rolefrom both an advisory and a facilitation point of view-and we must get back to building and maintaining the evidence base, we must return to long-term integrated planning and we must start to secure corridors, not only in our cities, but also between them, and we must ensure there is a transparent, rigorous project selection process, and that we get back to doing ex-post reviews.

Infrastructure Australia is focusing on these matters, and we are committed to provide more commentary on the issues in the wake of our 15-year plan. The plan was structured around four themes:

- productive cities, productive regions

- efficient infrastructure markets

- sustainable and equitable infrastructure

- better decisions, better delivery.

This planning process was not conducted in isolation, as we worked closely with our colleagues in the infrastructure agencies, organisations, governments and industry bodies across the country-focusing particularly on the long-term agenda. During the consultation process 
in which we travelled around the country talking about the audit, we have consulted with more than 500 people, including representatives of private organisations and governments, to seek their input into shaping this future plan.

We also met separately with state and territory governments to work together to solve some of the challenges we identified in the earlier audit to feed information into the plan. We received more than 85 submissions to the plan that helped inform our decisions; we have begun updating our Infrastructure Priority List and we have refreshed the way we consider projects as part of that process.

\section{Conclusion}

The main driver on which we need to focus at present is the scale of projected population change, which is something we have not seen before, particularly in our four largest capital cities. If we get this right, however, we can protect and enhance the quality of life we all enjoy. Infrastructure Australia must play a key role in supporting our collective long-term planning into the future. The plan we released in 2016 represents a major step forward in taking a solid evidence base and developing solutions to protect Australia's infrastructural future.

\section{References}

Australian Bureau of Statistics (ABS). (2013a). Australian Demographic Statistics: March Quarter 2013. Cat. no. 3101.0. Canberra: ABS. Available from: www. abs.gov.au/AUSSTATS/abs@.nsf/Lookup/3101.0Main+Features1Mar\%20 2013?OpenDocument

Australian Bureau of Statistics (ABS). (2013b). Population Projections, Australia, 2012 (base) to 2101. Cat. no. 3222.0. Canberra: ABS. Available from: www. abs.gov.au/AUSSTATS/abs@.nsf/DetailsPage/3222.02012\%20(base)\%20 to $\% 202101$ ?OpenDocument

Infrastructure Australia. (2016). Australian Infrastructure Plan: Priorities and Reforms for Our Nation's Future. Sydney: Infrastructure Australia. Available from: infrastructureaustralia.gov.au/policy-publications/publications/Australian -Infrastructure-Plan.aspx 
This text is taken from Road Pricing and Provision: Changed Traffic Conditions Ahead, edited by Michael de Percy and John Wanna, published 2018 by ANU Press, The Australian National University, Canberra, Australia.

doi.org/10.22459/RPP.07.2018.04 